Tropical Journal of Pharmaceutical Research December 2010; 9 (6): 587-593

(C) Pharmacotherapy Group,

Faculty of Pharmacy, University of Benin,

Benin City, 300001 Nigeria.

All rights reserved.

Available online at http://www.tjpr.org

Research Article

\title{
Reverse Phase High Pressure Liquid Chromatogra- phic Determination of Rifampin Quinone and Hydra- zone in Anti-tuberculosis Fixed-Dose Formulations Containing Sodium Ascorbate as Anti-oxidant
}

\section{P Umapathi*, J Ayyappan and Darlin Quine}

Department of Analytical Research and Development, Micro Labs Ltd, 67/68-A, Third Phase, Peenya Industrial Area, Bangalore 560 058, India.

\begin{abstract}
Purpose: To establish the method for the analysis of rifampin quinone and hydrazone in fixeddose combination tablets (FDC) containing rifampicin with or without sodium ascorbate as an additive. Methods: The International Pharmacopoeial (IP) method for the estimation of rifampin quinone in FDC was modified. The extraction solvent (methanol/buffer mixture) of the IP method was replaced with ethyl acetate, in order to stabilize rifampin quinone in sample solutions of FDC containing sodium ascorbate as an ingredient.

Results: Rifampin quinone in FDC samples containing sodium ascorbate, which is not detectable in the IP method, was found to be $1.15 \%$ (4-FDC), $1.52 \%$ (3-FDC) and $1.60 \%$ (2-FDC) using the modified method. Recovery of rifampin quinone in spiked samples of FDCs was practically nil in IP method whereas the recovery was $99.95 \%, 99.39$ and $99.02 \%$ for 4-FDC, 3-FDC and 2-FDC, respectively.

Conclusion: This modified method was suitable for the determination of rifampin quinone in fixed-dose formulations of rifampin both in the presence and absence of sodium ascorbate. The method is specific, precise, accurate, robust, rugged and gives a linear response for the quantitative estimation of rifampin quinone and hydrazone in fixed-dose combination tablets containing rifampin.
\end{abstract}

Keywords: Fixed dose combination; Rifampin quinone; Tuberculosis; Sodium ascorbate; Quantitative determination; HPLC 


\section{INTRODUCTION}

Fixed-dose combinations (FDC) of rifampin with other drugs, such as isoniazid (INH), pyrazinamide and ethambutal hydrochloride, is widely used for the treatment of tuberculosis. The International Pharmacopoeia (IP) has published monographs for some fixed-dose combinations which include related substances test. Some methods for estimation of the rifampin-related substances have been published in the literature [1-4]. From a formulation point of view, it is of paramount importance to keep these impurities within the specified limits $[5,6]$. Amongst the impurities of rifampin are rifampin quinone, which is an impurity formed from rifampicin by the process of oxidation [79], and anti-oxidants such as sodium ascorbate, are used in the tablets to control the formation of rifampin quinone during storage of the tablets.

The solvent mixture of methanol and buffer used in IP method for rifampin-related substances test in FDC rifampicin tablets is capable of dissolving sodium ascorbate and rifampin. Therefore, when this method is used for tablets containing sodium ascorbate as an additive, the sodium ascorbate which comes into solution in the sample preparation aids the conversion of rifampin quinone to rifampin in the sample preparation solution. On the basis of experiments to estimate rifampin quinone in FDCs containing sodium ascorbate using IP method at our laboratory, it was inferred that although rifampin quinone may be present in the tablet, IP method may not be able to accurately quantify this impurity since it gets converted to rifampin in the sample solution when sodium ascorbate is present. Therefore, the objective of this study was to substitute the extraction solvent of the IP method with another solvent in order to overcome this deficiency of the IP method.

\section{EXPERIMENTAL}

\section{Reagents and materials}

The reference standards - Rifampin USP (99.6\% pure) and Rifampin Quinone USP (98.6\% pure) were procured from Sandoz, India while 3-(isonicotinoylhydrazinomethyl) rifampicin [hydrazone] (95.5\% pure) was obtained from National Institute for Pharmaceutical Education and Research, India. Other materials used include potassium dihydrogen phosphate, ethyl acetate (analytical reagent grade, Qualigens, India), sodium hydroxide pellets (reagent grade) and methanol (HPLC grade, Merck, India). Water - purified with Millipore water system (Elix $10 \mathrm{C}$ model) - was used for the preparation of buffer and sodium hydroxide solution. PTFE membrane filters (Syringe filter - $25 \mathrm{~mm}$ GD/X- Whatman, $0.45 \mu$ ) were used for the filtration of standard and sample solutions. Cellulose acetate filter $(0.45 \mu$, Sartorium stedim) was used for the filtration of the mobile phase.

\section{Chromatographic conditions}

A Waters high performance liquid chromatographic (HPLC) system equipped with a 2695 solvent delivery system, Waters auto injector, thermostatted column compartment and Waters 2998 photo diode array detector were used for the experiment. The samples were analysed using a Kromasil column (Akzo Nobel, a C-18 column of $250 \mathrm{~mm} \times 4.6 \mathrm{~mm}$ i.d., $5 \mu$ particle size). A mixture of buffer and methanol in a ratio of 60:40 (v/v) was used as the mobile phase. The buffer for the mobile phase was prepared by dissolving about $1.36 \mathrm{~g}$ of potassium dihydrogen phosphate in $900 \mathrm{~mL}$ of water, adjusting the $\mathrm{pH}$ to $7.00 \pm 0.05$ using $0.1 \mathrm{M}$ sodium hydroxide and then making up the volume to $1000 \mathrm{~mL}$ with water. The buffer and methanol mixture was degassed by sonication and filtered through a $0.45 \mu$ cellulose acetate membrane filter. 


\section{Preparation of standard rifampin solution (Solution 1)}

About $2.5 \mathrm{mg}$ of rifampin powder was accurately weighed and transferred to a dry $10 \mathrm{~mL}$ volumetric flask. Ethyl acetate $(7 \mathrm{~mL})$ was added and the solution sonicated to dissolve the substance. The volume was then made up to $10 \mathrm{ml}$ with ethyl acetate. Out of this, $1 \mathrm{~mL}$ was diluted to $5 \mathrm{~mL}$ in a dry volumetric flask using ethyl acetate. Again, 1 $\mathrm{mL}$ of this solution was diluted to $5 \mathrm{~mL}$ using a diluent ( $\mathrm{pH} 7.0$ buffer: methanol, 60:40 v/v) in a $5 \mathrm{ml}$ volumetric flask to obtain a concentration of $10 \mu \mathrm{g} / \mathrm{mL}$ of rifampin.

\section{Solution for system suitability (Solution 2)}

About $2.5 \mathrm{mg}$ of 3-(isonicotinoylhydrazinomethyl) rifampicin, $2 \mathrm{mg}$ of rifampin quinone and $2.5 \mathrm{mg}$ of rifampin were accurately weighed and transferred to a dry $10 \mathrm{~mL}$ volumetric flask. About $7 \mathrm{~mL}$ of ethyl acetate was added and the solution was sonicated to dissolve the substances. The volume was then made up to $10 \mathrm{~mL}$ with ethyl acetate. Out of this, $1 \mathrm{~mL}$ of this solution was transferred to a $5 \mathrm{~mL}$ dry volumetric flask and made up to volume with ethyl acetate. Again, $1 \mathrm{~mL}$ of this solution was diluted to 5 $\mathrm{mL}$ using a diluent $(\mathrm{pH} 7.0$ buffer: methanol, $60: 40 \mathrm{v} / \mathrm{v}$ ) in a $5 \mathrm{~mL}$ volumetric flask to obtain a concentrations of $10 \mu \mathrm{g}$ of rifampin, $10 \mu \mathrm{g}$ of 3-(isonicotinoylhydrazinomethyl) rifampicin and $8 \mu \mathrm{g}$ of rifampin quinone, each per $\mathrm{mL}$.

\section{Preparation of test solutions as per proposed method (Solutions 3 - 5)}

Twenty 4-FDC tablets (i.e., comprising four drugs - rifampin, $\mathrm{INH}$, pyrazinamide and ethambutol $\mathrm{HCl}$ ) containing sodium ascorbate as one of the additives were powdered and an amount equivalent to about $100 \mathrm{mg}$ of rifampin was accurately weighed into a dry $100 \mathrm{~mL}$ volumetric flask. Ethyl acetate (70 $\mathrm{mL}$ ) was added and the flask shaken well. The volume was made up to $100 \mathrm{~mL}$ with ethyl acetate, mixed well, and then filtered through a $0.45 \mu$ PTFE membrane filter. The filtrate $(5 \mathrm{~mL})$ was diluted to $25 \mathrm{~mL}$ with a diluent (pH 7.0 buffer/methanol, 60:40 v/v) in a $25 \mathrm{~mL}$ volumetric flask (Solution 3). Test solutions of 3-FDC (Solution 4) and 2-FDC (Solution 5) were similarly prepared as above using the applicable tablet powder containing sodium ascorbate as one of the additives.

\section{Preparation of Test Solution as per IP method (Solutions 6-8)}

Twenty tablets of 4-FDC containing sodium ascorbate as one of the additives were powdered and an amount equivalent to 40 $\mathrm{mg}$ of rifampin was accurately weighed into a $200 \mathrm{~mL}$ volumetric flask. The diluent $(140 \mathrm{~mL}$, $\mathrm{pH} 7.0$ buffer: methanol, 60:40 v/v) was added, the flask shaken well and the volume was made up to $200 \mathrm{ml}$ with more of the diluents, and mixed well. The solution was filtered through a $0.45 \mu$ PTFE membrane filter to give Solution 6 . Test solutions of 3FDC (Solution 7) and 2-FDC (Solution 8) were similarly prepared using the applicable tablet powders containing sodium ascorbate as one of the additives.

\section{Preparation of spiked test solution as per proposed method (Solutions 9-11)}

Twenty tablets of 4-FDC containing sodium ascorbate as one of the additives were powdered and an amount equivalent to 100 $\mathrm{mg}$ of rifampin was accurately weighed into a dry $100 \mathrm{~mL}$ volumetric flask. 3(isonicotinoylhydrazinomethyl) rifampicin (5 $\mathrm{mg}$ ) and $4 \mathrm{mg}$ of rifampin quinone were transferred into this volumetric flask as well. Ethyl acetate $(70 \mathrm{~mL})$ was added and shaken well. The volume was made up to $100 \mathrm{ml}$ with ethyl acetate, mixed well and then filtered through a $0.45 \mu$ PTFE membrane filter. The filtrate $(5 \mathrm{~mL})$ was diluted to $25 \mathrm{~mL}$ with diluent [pH 7.0 buffer: methanol, 60:40 v/v] in a $25 \mathrm{~mL}$ volumetric flask (Solution 9). Test solutions of 3-FDC (Solution 10) and 2-FDC (Solution 11) were similarly prepared using the applicable tablet powder containing sodium ascorbate as one of the additives. 
Preparation of spiked test solution as per IP method (Solutions 12-14)

Twenty tablets of 4-FDC containing sodium ascorbate as one of the additives were powdered and an amount equivalent to $40 \mathrm{mg}$ of rifampin was accurately weighed into a 200 $\mathrm{mL}$ volumetric flask. 3-(isonicotinoylhydrazinomethyl) rifampicin $(2 \mathrm{mg})$ and $1.8 \mathrm{mg}$ of rifampin quinone were transferred into this volumetric flask. The diluent (140 $\mathrm{mL}, \mathrm{pH} 7.0$ buffer: methanol, 60:40 v/v) was added and the flask shaken well. The volume was made up to $200 \mathrm{~mL}$ with more of the diluent, mixed well and then filtered through a $0.45 \mu$ PTFE membrane filter (Solution 12). Test solutions of 3-FDC (Solution 13) and 2FDC (Solution 14) were similarly prepared using the applicable tablet powders containing sodium ascorbate as one of the additives.

Preparation of standard solution of rifampin quinone as per IP method (Solution 15)

Rifampin quinone (1.8 $\mathrm{mg}$ ) was dissolved and diluted to $200 \mathrm{~mL}$ with a diluent $(\mathrm{pH} 7.0$ buffer: methanol, $60: 40 \mathrm{v} / \mathrm{v}$ ) to obtain a solution of $8 \mu \mathrm{g} / \mathrm{mL}$ of rifampin quinone.

\section{Preparation of spiked solution of rifampin quinone in sodium ascorbate by IP method (Solution 16)}

Rifampin quinone $(1.8 \mathrm{mg})$ and $1.3 \mathrm{mg}$ sodium ascorbate were weighed accurately into a $200 \mathrm{~mL}$ volumetric flask. An amount $(140 \mathrm{~mL})$ of a diluent ( $\mathrm{pH} 7.0$ buffer: methanol, $60: 40 \mathrm{v} / \mathrm{v}$ ) was added and shaken well. The volume was made up to $200 \mathrm{~mL}$ with more of the diluent and mixed well.

\section{Chromatographic parameters}

For HPLC studies, a flow rate of $1.0 \mathrm{~mL} / \mathrm{min}$ and detection wavelength of $254 \mathrm{~nm}$ was used. The sample injection volume was $20 \mu \mathrm{L}$ and the column was maintained at ambient temperature of about $25{ }^{\circ} \mathrm{C}$. The run time for each injection was $60 \mathrm{~min}$.

\section{System suitability parameters}

In the chromatogram of system suitability solution, the resolution between 3(isonicotinoylhydrazinomethyl) rifampicin and rifampin quinone peaks should not be less than 4.0. Similarly, the resolution between rifampin quinone and rifampin peaks should not be less than 4.0. The \%RSD of area under the curve (AUC) values of rifampin peak in six replicate injections of standard solution should not be more than $2.0 \%$.

\section{Chromatographic studies}

An aliquot $(20 \mu \mathrm{L})$ of the prepared solutions (Solutions 1-16) were injected into the HPLC facility and their chromatograms were recorded.

\section{RESULTS}

The data in Table 1 show that when the proposed solvent system was used for the extraction of the tablet sample, the rifampin quinone in the sample solution was stable. The difference in AUC value of the rifampin quinone peak at $3 \mathrm{~h}$ compared to the initial AUC value ranged between 0.3 and $2.1 \%$. The recovery (\%) of rifampin quinone, using the proposed extraction solvent system (ethyl acetate), ranged between 99.0 and $101.1 \%$.

The results in Table 2 show that rifampin quinone was converted very rapidly in the sample solution to rifampin in the presence of sodium ascorbate when the sample was prepared as per IP method. Rifampin quinone was not detected when the extraction solvent of IP method was used (see Table 2). However, when IP method extraction solvent was changed to ethyl acetate in the proposed method, the test solutions showed the presence of 1.15 (4-FDC), 1.52 (3-FDC) and $1.60 \%$ (2 FDC) of rifampin quinone 
Table 1: Recovery and stability of rifampin quinone in ethyl acetate*

\begin{tabular}{|c|c|c|c|c|c|c|}
\hline \multirow{3}{*}{$\begin{array}{c}\text { Time } \\
\text { (h) }\end{array}$} & \multicolumn{6}{|c|}{ Rifampin quinone } \\
\hline & \multicolumn{3}{|c|}{ Solution stability (\% Difference) ${ }^{\mathrm{a}}$} & \multicolumn{3}{|c|}{$\%$ Recovery ${ }^{\text {b }}$} \\
\hline & 4-FDC & 3-FDC & 2-FDC & 4-FDC & 3-FDC & 2-FDC \\
\hline 3 & 1.0 & 2.1 & 0.3 & 99.00 & 99.39 & 99.02 \\
\hline 6 & 2.5 & 4.3 & 2.7 & to & to & to \\
\hline 9 & 5.2 & 8.7 & 5.6 & 100.12 & 101.14 & 99.65 \\
\hline 12 & 9.4 & 9.9 & 9.7 & & & \\
\hline
\end{tabular}

Table 2: Impurity and recovery data obtained as per International Pharmacopoeia (IP) and proposed methods

\begin{tabular}{|c|c|c|c|c|}
\hline \multirow[b]{3}{*}{ Sample } & \multicolumn{4}{|c|}{ Impurity (\%) } \\
\hline & \multicolumn{2}{|c|}{ IP method } & \multicolumn{2}{|c|}{ Proposed method } \\
\hline & Hydrazone & $\begin{array}{c}\text { Rifampin } \\
\text { quinone }\end{array}$ & Hydrazone & $\begin{array}{c}\text { Rifampin } \\
\text { quinone }\end{array}$ \\
\hline $\begin{array}{l}\text { Pure rifampin } \\
4-F D C \text { tablet } \\
\text { 3-FDC tablet } \\
\text { 2-FDC tablet }\end{array}$ & $\begin{array}{c}\text { Not detected } \\
1.59 \\
0.89 \\
0.85 \\
\end{array}$ & $\begin{array}{c}1.05 \\
\text { Not Detected } \\
\text { Not Detected } \\
\text { Not Detected }\end{array}$ & $\begin{array}{c}\text { Not detected } \\
1.63 \\
0.90 \\
0.89 \\
\end{array}$ & $\begin{array}{l}1.10 \\
1.15 \\
1.52 \\
1.60 \\
\end{array}$ \\
\hline & \multicolumn{4}{|c|}{ Recovery of impurity from spiked sample (\%) } \\
\hline $\begin{array}{l}\text { 4-FDC ablet } \\
\text { 3-FDC Tablet } \\
\text { 2-FDC Tablet }\end{array}$ & $\begin{array}{c}101.89 \\
98.82 \\
100.28\end{array}$ & $\begin{array}{l}\text { Not Detected } \\
\text { Not Detected } \\
\text { Not Detected }\end{array}$ & $\begin{array}{l}98.80 \\
98.50 \\
99.00\end{array}$ & $\begin{array}{l}99.95 \\
99.39 \\
99.02\end{array}$ \\
\hline
\end{tabular}

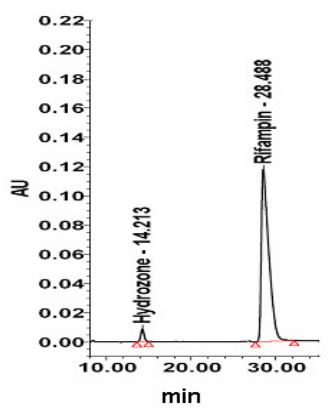

(A)

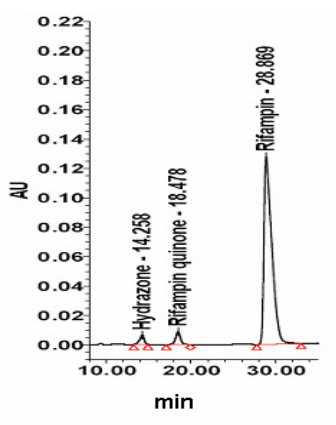

(B)
Figure 1: $(A)=$ Spiked sample of 4-FDC test solution prepared by International Pharmacopoeia (IP) method diluent (rifampin quinone $8 \mathrm{ppm}+$ hydrazone 10 ppm spiked to sample); (B) = Spiked sample of 4-FDC test solution prepared by proposed method diluent (rifampin quinone 8 ppm + hydrazone 10ppm spiked to sample

To verify the suitability of the proposed method for the determination of hydrazone and rifampin quinone in 4-FDC, 3-FDC and 2-
FDC tablets containing sodium ascorbate as an additive, the proposed method was validated for these FDCs and the results of the method validation for 4-FDC tablets are presented in Table 3 . The validation data, including specificity, linearity, range, accuracy, precision, robustness, limit of detection and solution stability were all within the acceptance criterion for the FDCs.

\section{DISCUSSION}

The International Pharmacopoeia (IP) method extraction solvent/diluent dissolves sodium ascorbate thus resulting in the conversion of rifampin quinone to rifampin in test sample preparations. The results show that the conversion of rifampin quinone to rifampin is so rapid that the chromatograms of the test preparations did not show any rifampin quinone peak when the solutions 
Table 3: Method validation data for 4-FDC tablets

\begin{tabular}{lccc}
\hline Parameter & Hydrazone & Rifampin quinone & Acceptance criteria \\
\hline Specificity & No interference & No interference & $\begin{array}{c}\text { Interference should be } \\
\text { NIL. }\end{array}$ \\
Linearity (R) & 1.000 & & $>0.990$ \\
Response factor & 1.92 & 1.000 & - \\
Range & 0.4 to $15.0 \mathrm{ppm}$ & 0.2 to $12.00 \mathrm{ppm}$ & - \\
Accuracy & 99.00 to $100.12 \%$ & 99.15 to $100.05 \%$ & $90-110 \%$ \\
Precision (\%RSD) & $0.9 \%$ & $0.5 \%$ & $\leq 10 \%$ \\
Intermediate precision & $0.9 \%$ & $0.9 \%$ & $\leq 10 \%$ \\
Robustness & & & RRT $~ 0.5$ (hydrazone \\
Change in flow rate & 0.49 & 0.65 to 0.68 & \& 0.6 (rifampin quinone) \\
Wavelength & 0.49 & 0.64 & \\
Mobile phase composition & 0.45 to 0.51 & 0.72 to 0.77 & - \\
Limit of detection (LOD) & $0.133 \mathrm{ppm}$ & $0.067 \mathrm{ppm}$ & $\leq 10 \%$ \\
Solution stability & $(\%$ Difference) & $(\%)$ Difference) & \\
& After $3 \mathrm{~h}$ & 0.4 & 1.0 \\
& After $6 \mathrm{~h}$ & 1.1 & 2.5 \\
& After $9 \mathrm{~h}$ & 1.3 & 5.2 \\
& After $12 \mathrm{~h}$ & 1.9 & 9.4 \\
\hline \% Difference = reduction in AUC values of the impurity peaks relative to the initial AUC value
\end{tabular}

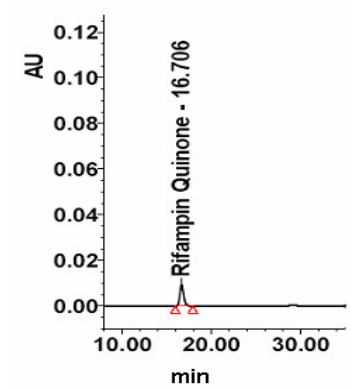

(A)

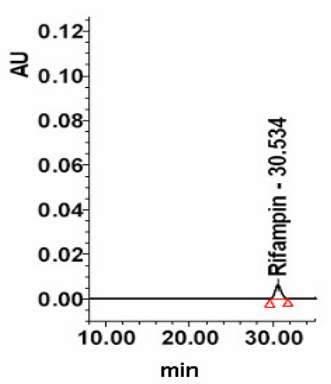

(B)
Figure 2: $(A)=$ rifampin quinone solution (8 ppm) prepared with International Pharmacopoeial method diluents; $(\mathrm{B})=$ rifampin quinone solution $(8 \mathrm{ppm})$ spiked with sodium ascorbate $1.65 \mathrm{ppm}$ solution.(Diluent used: As per International Pharmacopoeial method)

were prepared as per the IP method (Figure 2 ). It is worth noting that in the case of pure rifampin, recovery data for rifampin quinone were comparable for both IP method and the proposed method.

Literature reports indicate that rifampin quinone is formed from rifampin by oxidation [7-9]. Many of the FDCs containing rifampin are likely to have sodium ascorbate as one of the additives to control the formation of rifampin quinone from rifampin in the tablet. The current International Pharmacopoeial method for estimation of rifampin-related substances in 4-FDC, 3-FDC and 2-FDC is unsuitable for the estimation of rifampin quinone in the FDCs containing sodium ascorbate as one of the additives since the solvent mixture of buffer and methanol used for the initial dilution of the sample dissolves sodium ascorbate.

\section{CONCLUSION}

The developed method which entails a change in the solvent for the initial dilution of the FDC tablet samples containing sodium ascorbate as an additive would, unlike the IP method, lead to accurate quantitation of rifampin quinone and hydrazone impurity as evidenced by the results presented in this study. The developed method was successfully validated, is stability-indicating, and can be routinely used for the determination of hydrazone and rifampin quinone impurities in FDCs containing sodium ascorbate as an additive. 


\section{ACKNOWLEDGEMENT}

This work was supported by Micro Labs Limited., India and Shanmuga Arts, Science, Technology \& Research Academy, India.

\section{REFERENCES}

1. International Pharmacopoeia Fourth Edition, 2008. Rifampicin, isoniazid, pyrazinamide and ethambutol hydrochloride tablets. (Available from:

http://apps.who.int/phint/en/p/docf/anchor, readi ng-docs.html). [cited 2010, March 8]

2. Jianfang $L$, Jin $S$, Wei $Z$, Kun $G$, Zhonggui $H$. HPLC determination of rifampicin and related compounds in pharmaceuticals using monolithic column. J. Pharm. Biomed. Anal. 2008; 46: 405-409.

3. Mohan B, Sharda N, Singh S. Evaluation of the recently reported USP gradient HPLC method for analysis of anti-tuberculosis drugs for its ability to resolve degradation products of rifampicin. J. Pharm. Biomed. Anal. 2003; 31 : 607-612.

4. Graham KC, Lebelle MJ, Wilson WL.. High Performance Liquid Chromatographic Analysis of Rifampin and Related Impurities in Pharmaceutical Formulations, J. Liq. Chromatogr. Rel. Tech. 1979; 2: 365-371.

5. Sarjanjit S, Mariappan TT, Sankar R, Sarda N, Baljinder S. A critical review of the probable reasons for the poor/ variable bioavailability of rifampicin from anti-tubercular fixed-dose combination (FDC) products, and the likely solutions to the problem, Int. J. Pharm., 2001; 228: 5-17.

6. Sankar R, Nishi S, Saranjit S. Behavior of Decomposition of Rifampicin in the Presence of Isoniazid in the $\mathrm{pH}$ Range 1-3. Drug Dev. Ind. Phram. 2003 ; 29:733-738.

7. Rao BS, Murthy KVR. Development of dissolution medium for rifampicin sustained release formulations. Indian J Pharm Sci. 2001; 63: 258-260.

8. Fernanda de Jesus $N$, Valdecir FX, Luiz M, Olga $M$, Iguatemy L. Horseradish PeroxidaseCatalyzed Oxidation of Rifampicin: Reaction Rate Enhancement by Co-oxidation with Antiinflammatory Drugs. Biol. Pharm. Bull. 2005; 28:1822-1826.

9. Bolt HM, Remmer $H$. Implication of rifampicinquinone in the irreversible binding of rifampicin to macromolecules. Xenobiotica. 1976; 6: 2132. 